\title{
Subjetividad y tiempo en la construcción de \\ la utopía
}

\section{Introducción}

La política, como capacidad de hacer y de promover del hombre, lleva contenido un desafío, aquél de cuestionar la inercia del propio hacerse de la historia cuando

La política, como capacidad de hacer y promover del hombre, lleva contenido un desafío, aquél de cuestionar la propia inercia de la historia.

La política como praxis es un desafío a la conciencia del hombre y un llamado a

construir un espacio por definirse.

Es en este contexto en el cual pretende recuperarse la utopía como capacidad y

posibilidad de hacer posible, viable y objetivable aquello que se presenta como un horizonte; en la medida en que éste nos motiva a acudir también nos invita a construir, que tiene que ver con la creación del sueño.

- Profesor-Investigador del Departamento de Estudios Ibéricos y Latinoamericanos del Centro Universitario de Ciencias Sociales y Humanidades.

afignoni@ csh.udg.mx ésta obedece a una evolución progre siva y natural, librada a la suerte de leyes históricas, rígidas e inel uctables. La política como praxis es un desafío a la propia conciencia del hombre, un llamado a construir un espacio por definirse, por inaugurarse. El concepto de práctica, la realidad humano-social, se presenta como lo opuesto al ser dado, es decir, como aquello que forma el ser humano, a la vez es una forma específica de él. La praxis es la esfera del ser humano. La existencia no sólo se enriquece con la obra humana, sino que en ella y en la creación del hombre-como en un proceso ontocreador- se manifiesta la realidad (Kosik, 1967:240).

La realidad es una forma de apelación de las múltiples realidades contenidas en ella: constreñidas, desbordadas, desplegadas, anidadas, virtuales. Este magma potencial fecundo, que espera al hombre 
con su inmensa fuerza creadora del HACER, se mueve en espacios generados por la dialéctica de fuerzas encontradas que se disputan, se anulan, se equilibran; está abierto a la construcción de nuevos espacios. En este campo de luchas diversas hay un terreno para el despliegue de nuevas corrientes que tienen que ver con la voluntad y la capacidad del hombre de actuar en y sobresu propia realidad. Es una posibilidad, una opción por asumir la responsabilidad que le compete al hombre en tanto ser político y social de definir, perfilar y dibujar los contornos que respondan a sus propias necesidades históricas.

Este situarse requiere del conocimiento acerca de la multiplicidad de fenómenos que hacen compleja a la realidad; de la conciencia del tiempo del hombre, de su tiempo que lo historiza, que lo carga de sentido (la aprehensión de lo global que configura su mundo) y fundamentalmente de la voluntad como una disposición-fuerza del sujeto por generar un movimiento que lo ubique en un horizonte distinto.

La conciencia es movimi ento, puesto que constituye un inmenso potencial. Ésta es necesidad de plasmar deseos, de concretar utopías, de dotar el estar del hombre en el mundo de un nuevo y fecundo compromiso, de permitirle desplegar todos sus recursos (los de su más íntima subjetividad) en la búsqueda de un mundo más humano, en donde lo subjetivo encuentre su cauce en lo social. La conciencia debe ser también el motor de la acción. Cuando esta conciencia lo empuja a hacer, y pensamiento y acción son sólo momentos de un mismo movimiento que sigue una dirección, el hombre es coherencia y unidad con la realidad que él mismo va definiendo. En este sentido, la conciencia implica esperanza (esperanza que no es abandono y espera, sino vol untad y compromiso), pero la acción es una búsqueda más nítida que impulsa al hombrea umbrales que él mismo puede visl umbrar. Es como un salto que busca concretar esa utopía de futuro en un tiempo presente; la acción es la concreción de la utopía traducida 
en proyectos concretos y viables. Puede decirse que la práctica es una dirección realizada, por lo tanto, una particular re solución de tiempo y espacio según determinadas opciones reconocidas y elegidas (Zemelman, 1997:108).

EI hombre crea la historia y vive en la historia mucho antes de conocerse a sí mismo como ser histórico. Para Aron, cada col ectividad tiene una conciencia histórica, una idea de lo que significa para ella humanidad, civilización, nación, el pasado y el porvenir, los cambios a los que se hallan sujetado, a través del tiempo, las obras y las ciudades (Aron, 1962:79).

La búsqueda de lo utópico de la historia lleva al hombre a cuestionar la linealidad del tiempo, porque el pasado es la carga histórica del presente hecha conciencia, no es un tiempo transcurrido, coexiste con el presente por cuanto la memoria la llena de contenido y desde su movimiento permite avizorar un tiempo por-venir que insta a su concreción.

Por lo tanto el aún-no, lo virtual del tiempo, Io no devenido, Ileva ínsita la fuerza que llama a su propia realización. Esta coetaneidad quiebra un sentido único del tiempo, lo amplía, lo hace complejo. Esto implica cuestionar la lógica del poder, su naturaleza, su cerrazón, el repliegue sobre su propia forma que apunta a cristalizar una única opción concebible.

EI actor como agente creador es aquél que transgrede las barreras impuestas por el paradigma dominante, quien rompe su lógica y se abre, en su capacidad de reactuación sobre circunstancias determinadas a caminos diversos, para determinar su propio desenvol vimiento sociohistórico.

Si la historia debe ser vista como innumerables campos de acción, la acción debe ser entendida como coexistencia de tiempos múltiples.

Política y subjetividad

Si pensamos que la búsqueda de la satisfacción de las necesidades básicas mueve forzosamente a los individuos a su 
realización, podríamos inferir que las estructuras de poder dejan espacios abiertos para que los sujetos, conscientes de sus necesi dades, se lancen a la concreción de sus deseos. Pero esto no ocurre necesariamente así. Las estructuras dominantes minan la conciencia del hombre e influyen sobre su capacidad de movimiento para alterar la realidad. Muchas veces existen sólo intersticios que únicamente algunos hombres pueden percibir. Cierto es también que cuando hablamos de necesidades nos internamos en un terreno complejo, puesto que las necesidades son fronteras movibles; aquello que se experimenta como necesario en un momento histórico puede ser no sentido como necesario en otro.

Indudablemente, el problema de las necesidades tiene que ver con la conciencia de dichas necesidades, pero también con la coyuntura que permita a los sujetos sociales moverse en una lucha que busque viabilidad para la concreción de las mismas. Por eso, aunque el poder como estructura estática y avasallante intente achicar estos espacios de confrontación, el sujeto puede desplegar su fuerza creadora y orientarla a la materialización de realidades más propicias para su desenvolvimiento. Según Emma León, las prácticas y subjetividades, más allá de optimismos ingenuos, tienen que considerarse a la luz de la correlación de fuerzas que operan en distintos tipos de realidades, poniendo en antagonismo, competencia o armonización diversos proyectos de vida que tratan de imponer márgenes importantes al desenvolvimiento de un sujeto y su socialidad (León, 1997:62). En este sentido, la libertad no es un estado, sino la actividad histórica que crea las formas correspondientes de convivencia humana, es decir, de espacio social.

El sujeto es un ser individual, pero también es un ser social. La individualidad es conciencia, vivencia, experiencia y, en este sentido, también es potencia, de lo que es, por cuanto el hombre es un hacerse con su historia, inacabado y moldeable. La realidad se construye con base en una relación dialé- 
ctica, en donde el desafío del hombre es ganar espacios que le permitan estar siendo con otros, con quienes, a su vez, carga su experiencia y por lo tanto su existencia de sentido.

Por esta razón, todo análisis del hombre que lo visualice como rígido e inflexible cierra el horizonte de opciones que éste puede perfilar. Esta perspectiva lo congela y lo concibe como producto y no como producente. EI movimiento de lo real en su transformación refleja el propio movimiento del hombre, cuyo motor es la necesidad de objetivación de la utopía como necesidad histórica. La contradicción entre individuo y sociedad se plantea cuando el desenvolvimiento histórico constriñe el desenvolvimiento de la subjetividad y, por lo tanto, de las necesidades de éste, de sus deseos, de sus sueños.

En este sentido, la praxis comprende un el emento existencial que se manifiesta tanto en la actividad objetiva del hombre, transformadora de la natural eza y donadora de sentido humano al material natural, como en la formación de la subjetividad humana, en la creación del sujeto humano, en la cual los aspectos existenciales (angustia, miedo, alegría, risa, esperanza, etc.) no se presentan como experiencia pasiva, sino como parte de la lucha por el reconocimiento, o proceso de real ización de la libertad humana (Kosik, 1967:243).

Para ser sujeto pleno, el hombre debe conquistar su libertad a partir de un camino que éste debe forjarse. La libertad supone la responsabilidad de asumir el destino en sus manos, de ser artífice de su circunstancias. Es en este sentido que ser sujeto protagónico implica el paso de la conciencia a la acción, a la creación, al proyecto, y contiene la fuerza puesta al servicio de su enorme potencialidad y voluntad para hacer posible su realización. La potencialidad contiene la memoria, la capacidad de actualizar el pasado, de tomar la huella y cargarla de nuevos sentidos, puesto que el presente no refleja el pasado tal cual fue; de recuperar lo que aún no ha caducado porque su potencialidad no desplegada, pero 
susceptible de serlo, le confiere vigencia. Muchas de las grandes utopías no fracasaron, más bien nunca se desplegaron: esto implica un desafío, una tarea pendiente. Pero para que éstas sean realizables deben anclarse en realidades y posibilidades susceptibles de materializarse, que tendrá que ver con la propia maduración del sujeto de generar tiempos y espacios de cambio hacia nuevos rumbos, ver a través de ventanas que vislumbren horizontes más cercanos y alcanzables (Zemelman, 1989:87).

Para esto, el hombre debe hacerse de nuevos campos, propicios para ampliar los límites de su quehacer, alimentar su voluntad de vivir, de sentir (en y con el mundo), de dotar de sentido su vida, de un sentido trascendente que valide su existencia, que lo anime, que lo movilice, que recupere lo que hay de más humano y el evado en él, que sea capaz de vibrar con el mundo, con su mundo, porque el mundo es el múltiple latir de sujetos vivos.

La conciencia es como la semilla que, aunque anidada en tierra fértil, necesita del tiempo para florecer. De ahí la significación de la memoria: recupera el momento fecundo de la concepción, pero se nutre del fruto en el presente capaz de trascender su propio tiempo.

Ahora bien, plantear la necesidad de un desarrollo social y humano del sujeto nos Ilevaría a cuestionar las estructuras en las cuales está inserto y, por lo tanto, a entrever nuevas opciones de su relación con lo social. El trabajo, si bien no agota todo el ámbito de expresión de la subjetividad, es una forma de inserción del individuo en la esfera de lo social. Esto nos Ilevaría a plantearnos qué otras opciones existen, en términos de rescatar en el trabajo al sujeto creador, que se dignifica porque moviliza su fuerza y la poneal servicio de lo comunitario. Pero las relaciones de dominación impuestas por el capitalismo no estimulan este despliegue. Por el contrario, lo someten a pautas externas a la propia naturaleza humana, porque el énfasis está puesto en la necesidad de 
reproducción del sistema. Dice F romm: “Tras la fachada cristiana surge una nueva y secreta religión industrial, que está enraizada en la estructura del carácter de la sociedad moderna, pero que no se conoce como religión. Ésta reduce a los individuos a la calidad de servidores de la economía y de la maquinaria que construyen con sus propias manos" (Fromm, 1996:142). Esta relación de dominación significa un obstáculo para la ampliación de la conciencia e implica, en consecuencia, un impedimento para la transformación del hombre histórico en sujeto.

Estas formas perversas restringen la autonomía del sujetoy, por lo tanto, son un desafío a su capacidad para promover nuevos perfiles en la organización del trabajo. Pero el hombre no está recluido en su animalidad o en su socialidad, porque no sól o es un ser antropológico, sino que está abierto a la comprensión del ser sobre la base de la praxis; es, por lo tanto, un ser antropocósmico.

En el capitalismo actual, la práctica se identifica con la técnica, entendida y practicada como manipulación, como técnica operativa, como arte de disponer de los hombres y las cosas. Este cambio impli có un nuevo concepto de hombre, mundo y verdad (Kosik, 1967:236).

La tecnología no está puesta al servicio de la promoción del hombre, de su superación, sino que provoca su alienación. De la misma manera, los medios de comunicación de masas apuntan a la estandarización del individuo. Homogeneizar es alinear, es construir un prototipo de sociedad de hombres producidos en serie, donde lo auténtico y propio de cada ser se desdibuja y las múltiples identidades se diluyen en un perfil de identidad exclusiva y aceptable.

Es necesario que el individuo defina cuál es el ámbito desde el cual actuar sobre lo macrosocial. Lo local como microespacio constituye la dimensión privilegiada desde donde avizorar nuevas perspectivas de desenvolvimiento y el germen de constitución de micro movimientos de acción. 
É ste será un terreno de continuidades y quiebres, porque lo dialéctico rompe con una acción lineal de la construcción misma, ya que ésta será mediada por determinaciones que el hombre en su lucha deberá vencer. La construcción social es dicotómica: es realidad objetivada y es movimiento. En este sentido, tiempo y espacio son construcciones social es que se van estructurando en razón del propio movimiento de los sujetos. Éstos tienen la capacidad de conferirle sentido o más precisamente múltiples sentidos a sus propias prácticas sociales; o sea, que la subjetividad tiene el rol de imprimir cargas potenciales a sus prácticas. Una dirección puede ser destructora, pero también puede ser de desarrollo.

La confrontación de estas múltiples direcciones en el espacio social es una dimensión privilegiada de lo político, porque le otorga a los sujetos la posibilidad de hacerse con otros y movilizar las subjetividades diferenciadas, las que, desde su inmensa complejidad, enriquecen la trama de lo social. Así, el movimiento constituyente de las subjetividades permite delinear los perfiles de la historia, y sujetos e historia se imbrican en un movimiento dialéctico que los va definiendo, en donde el sujeto se historiza y la historia se va sedimentando como el magma de múltiples subjetividades.

Política y tiempo

"El recuerdo es para los que han olvidado"

Plotino

La política como movimiento cuestiona la concepción de un tiempo lineal, en donde el tiempo a su vez es una exigencia de conocimiento. La concepción lineal del tiempo responde a una visión estática de la realidad, acotada a los límites del ahora. Pensar que el pasado es sól o y únicamente un tiempo devenido, transcurrido, acabado, sin consecuencias para el tiempo presente y sin permanencia en el hoy, es ne- 
gar la memoria que no sól o recupera lo acontecido, sino que lo mantiene vivo, nítido. El contenido mismo de la política, en su capacidad de hacer, Ileva una carga que lo proyecta en dirección al futuro que busca realizar la utopía como concreción del futuro en el presente.

Los pueblos que perdieron la memoria negaron su historia, achicaron su visión del presente y comprometieron la construcción de su futuro.

El análisis político debe reconocer la centralidad del tiempo en los procesos sociales, puesto que éste devela no sólo la secuencialidad de los fenómenos, la especificidad de las coyunturas, sino también la coetaneidad de temporalidades múltiples y variadas.

La multiplicidad del tiempo no sól o se relaciona con la simultanei dad que hace a la complejidad de la realidad, sino con sentidos diversos contenidos en esa pluralidad, sentidos que coexisten, que subyacen, que se manifiestan.

Es interesante cómo Borges hace explícita, desde la narrativa hispanoamericana, una cronotopía moderna. Sus relatos son incomprensibles sin la inteligencia de una diversidad de tiempos y espacios que revelan una diversidad de culturas. Dice este autor que las excentricidades de Herder -sól o Europa es histórica- o de Hegel -América es un todavía no, un noumdum- dejaron de ser centrales cuando la violencia histórica general izada del siglo XX demostró que todos somos excéntricos y que ser excéntricos es la única forma de ser central. Esta nueva ubicación, en la que la cultura absoluta y central desaparece, para convertirse en la suma, tensión y aportación de culturas variadas, implica también un nuevo tiempo en el que no se le niega presente al pasado, pues éste puede ser, en efecto, el único presente de una cultura viviente (Fuentes, 1990:43).

El capitalismo, en tanto cosmovisión hegemónica, impuso la existencia de un tiempo único que se relaciona con la necesidad del hombre de adecuarse a las nuevas formas de orga- 
nización del trabajo: el tiempo de la producción como tiempo creado, artificial, configurado en torno a la capacidad del hombre de generar riqueza al servicio del capitalismo naciente. No es el tiempo que dignifica, el tiempo que despliega la creatividad, el tiempo que mueve al hombre a la realización de una parte importante de su subjetividad en el trabajo. Éste es el tiempo que transforma lo natural y espontáneo en lo artificial como necesidad, como fundamento de una enorme estructura en la que el hombre, minimizado y empobrecido, Ianza consciente un grito de alerta, se proyecta hacia su propia recuperación, la de su tiempo, de sus espacios, de su propia supervivencia.

La visión lineal del tiempo se enmarca en un paradigma cuya premisa es el progreso. El progreso como única secuencia ordenada de fenómenos que se ajustan invariablementea una exclusiva concepción del tiempo.

América Latina, en tanto configuración histórica, es un campo fértil de tiempos diferenciados. Las culturas ancestrales vivieron otras nociones de tiempo: aquél relacionado con las estaciones, con la siembra, el tiempo solar.

Fue justamente el progreso traído a nuestro continente por la modernidad el que se superpuso a aquellos otros tiempos. Y los tiempos del progreso combatieron a los tiempos ancestrales por anacrónicos, por disfuncionales a la dinámica impuesta por el desarrollo, un desarrollo ahistórico porque surgió de concepciones extrañas a nuestra forma de ver y sentir. Desde esta perspectiva hegemónica, el desarrollo llegaría a América Latina cuando se agotaran las etapas necesarias e ineluctables para arribar a estadios más avanzados, desconociendo los contextos disímiles y las historias particulares.

La afirmación de la aceptación de un tiempo distinto niega la posibilidad de existencia de otros tiempos, pero también niega toda forma diferenciada de manifestación del ser, de lo disímil, de lo diverso, ya que lo considera una perver- 
sión de lo auténtico, de lo genuino. Inclusive negar la alteridad necesaria para la definición de identidades (ya que lo uno se constituye en relación a la existencia de lo otro) llevó a la implacable destrucción de lo otro.

Los tiempos históricos conllevan una mutación propia, dada por las subjetividades sociales que son portadoras de múltiples historias posibles, como de aquéllas que caen presa de determinaciones. Pero, indudablemente, el tiempo lleva la impresión de lo colectivo. Ha estado presente en el pensamiento humano como preocupación fundamental.

En este vasto horizonte tejido de tiempos múl tiples, el hombre, consciente de su contexto histórico, se lanza a la conquista de tiempos por inaugurar, en donde éste pueda ser desde su memoria (que mantiene vivo el pasado), desde su presente (que lo impulsa a un movimiento hacia adelante, hacia la construcción), desde su futuro (que acorta la distancia porque la utopía es el impulso de la conciencia).

\section{Política y utopía}

En el quehacer político, la política como dinámica empuja al sujeto a la construcción de nuevos sentidos. Estos múltiples sentidos posibles están cargados de valores que orientan la acción del hombre. Por eso, cuando hablamos de proyectos, hablamos también de utopías, puesto que la carga axiológica de la voluntad social prefigura de manera innovadora la transformación de la realidad. La dinámica política tiene a las utopías sociales como el punto de arranque para su posterior despliegue. La utopía es la punta de lanza de un proyecto que busca su viabilidad, su objetivación en realidades palpables y concretas. Porque son la necesidad de algo, de que algo nuevo no sól o se vislumbre en el horizonte, sino la concreción de un horizonte nuevo que se pueda hacer realidad. De allí la significación y pertinencia de un pensamiento libertario, auténtico, que permita ajustar los proyectos a las 
necesidades históricas de América Latina, porque el pensamiento es un pensamiento que, consciente de las identidades propias de un pueblo como premisa, permite desplegar una acción pertinente a las necesidades históricas. Por eso, la enorme significación de los valores en la conformación de las conciencias. La latinoamericanidad es la matriz de valores nuevos (Luminato, 1995:30). Esto implica conocer y asumir la propia historia y entender y asumir la propia realidad; esta realidad como magma constitutivo de lo auténtico y de lo germinal.

La política, como la capacidad del hombre de pensar, implica la teorización acerca de la realidad orientada a nuevos horizontes de realidades que puedan ser desplegadas. Por eso, la viabilidad es parte necesaria y constitutiva del quehacer político. La política debe atender a las necesidades de concreción a través del actuar consciente y organizado, en donde el hombre pone su voluntad al servicio de lo social. De allí la importancia de la conciencia histórica como punto de partida del movimiento que la capacidad creadora del hombre utiliza para apuntar a la objetivación a través de direcciones definidas. Este involucramiento del hombre en lo social implica el compromiso que tendría como finalidad el cambio. Lo valórico orienta el cambio en determinada dirección.

Preguntarse qué es América Latina es el ángulo, el episteme, pero preguntarse qué será América Latina involucra a lo político como movimiento que es la acción, la construcción de aquello que creemos posible. Para Susana Luminato, lo epistémico también remite a lo político a través de los valores. Por eso, el pensamiento libertario es un pensamiento (un ángulo de lectura de la realidad), pero también es ético y político porque los valores contenidos en él como premisa, basados en utopías, conllevan la necesidad de hacer viable lo posible (Luminato, 1995:47). Este pensar Ileva ímplícita la necesidad de actuar, porque el cambio hacia una 
dirección es visto como una necesidad histórica. Por eso, si bien el neoliberalismo contiene una utopía como motor, es ahistórico porque no surge como necesidad desde América Latina, sino como imposición desde otras latitudes ajenas y extrañas a ésta, nuestra realidad histórica. En el plano axiológico es antiético, pues promueve contravalores que exacerban la negatividad del hombre. Según lo plantea Kurnitzky, el estilo de la vida posmodernista permite escapar del mundo con su oferta de atracciones y vivencias. El víncul o emocional a los objetos, a su utilidad, viene a ser sustituido por la orgía de atracciones y vivencias en la que el sujeto se disuelve (Kurnitzky, 1998:69). De allí el vaciamiento de lo político como quehacer y premisa del construir, porque la política es negada como espacio de confrontación y de lucha por la satisfacción de las necesidades del hombre y su dignificación. Por lo tanto, los técnicos asumen esta actividad como una dinámica exenta de sensibilidad y, en consecuencia, la racionalidad técnica se impregna de contenido ideológico (como lo plantea Habermas, 1981:145).

La reapropiación de lo político apunta a la materialización de la democracia real, porque abre los espacios de despliegue del hacer que el vaciamiento de lo político constriñe, hecho que implica necesariamente el achicamiento del sujeto y de su espíritu creador que, en lo social, sól o se manifiesta en lo político como espacio privilegiado de organización y consenso.

Ahora bien, la utopía como motor debe surgir de la propia conciencia del hombre como necesidad histórica. Debe estar presente en cada conciencia, debe estar contenida en un pensamiento acerca de la necesidad de aquello que queremos construir. Pero debe partir de un análisis real de la sociedad, de una constatación del deseo compartido de los individuos de perfilar una sociedad diferente. Cuando se idealiza a los sujetos, la utopía pierde su contenido histórico, porque parte de una realidad que no existe, por lo tanto se desdibuja su 
viabilidad, pierde su sustento y razón de ser. La utopía como proyecto puede ser rescatada, pero desde la necesi dad y la voluntad compartida que mueva a su concreción. Ciorán se preguntaría qué sentido tiene formar una sociedad de marionetas. Lo que más impresiona en los escritos utópicos, dice este autor, es la ausencia de ol fato, de instinto psicológico: los personajes son autómatas, ficciones o símbolos, ninguno es verdadero, ninguno sobrepasa su condición de fantoche, de idea perdida en medio de un universo de referencias.

Al abolir lo irracional y lo irreparable, la utopía se opone también a la tragedia, paroxismo y quintaesencia de la historia. Cualquier conflicto desaparecería en una ciudad perfecta; las voluntades serían estranguladas, apaciguadas y milagrosamente convergentes; reinaría únicamente la unidad, sin el ingrediente del azar o de la contradicción. La utopía es una mezcla de racionalismo pueril y de angelidad secularizada (Ciorán, 1988:125).

Lo que ocurrió en América Latina fue que la utopía se planteó en el marco de una racionalidad cultural, pero no se movieron las fuerzas necesarias para la transformación de la realidad.

Por lo tanto no se potenció lo potenciable y la utopía se transformó en fantasía. Hoy, frente a la política como eficacia y a la apatía de los sujetos, la utopía se proyecta como desafío, como desbloqueo que implica la capacidad del hombre de tomar distancia y ser sujeto de la historia, de su propia historia, el paso de ser sujeto de a ser sujeto ante (Zemelman, 1989:92).

Esta última consi deración no sól o es epistémica, también es política porque empuja al hombre a transgredir las fronteras de lo permitido, de lo concebido desde una visión hegemónica de poder. Porque el poder no está puesto al servicio de construir, sino de legitimar una única forma de realidad.

En este sentido, el neoliberalismo rompe la relación entre lo histórico y lo político. Porque lo político es el camino de 
construcción de la historia, es el afrontamiento a un orden finalista o teleol ógico de la historia.

El quehacer político supone confrontación y rebasa los límites de lo real, porque lo real es únicamente lo dado. Para el neoliberalismo, el hacer del hombre es percibido como una afronta al propio Dios que legitima una única historia posible.

Si bien esta concepción ideológica partió de su propia utopía, los valores contenidos en ella niegan lo político como apertura, como divergencia y dialéctica, incluso como superación y movimiento de la historia. Las leyes del mercado, y por lo tanto de la historia, le atribuyen una connotación determinista que niega la capacidad de hacer del hombre sacudido por sus deseos y necesi dades (léase preferencias).

En este sentido se puede afirmar que la utopía es portadora de val ores que alientan la conformación de una conciencia histórica. Para Raymond Aron existen tres elementos de la conciencia histórica: la conciencia de una dialéctica entre tradición y libertad, el esfuerzo para captar la realidad o la verdad del pasado, el sentimiento de que la sucesión de organizaciones sociales y creaciones humanas a través del tiempo no es una sucesión cualquiera o indiferente, de que concierne al hombre en lo que éste tiene de esencial (Aron, 1962:72 y 73).

Si la utopía es conciencia, la política es necesidad de despliegue de esa misma conciencia en proyectos y en direcciones, que busca su espacio de objetivación.

La utopía se cristaliza en una opción política y cultural que busca viabilizarse a través de la fuerza de la direccionalidad que el hombre le imprime en su andar. De ahí la pertinencia de lo histórico, de un pensamiento que surja en y desdeAmérica Latina, que retome su propia matriz cultural, la recupere y se apropie de ella. Negar su identidad es desfigurar los proyectos históricos, que llevan contenido el fracaso de lo ahistórico. 
Por eso, hoy la realidad se plantea como un desafío; ella misma contiene otras realidades susceptibles de dibujarse y llenarse de contenidos ricos y fecundos. Porque el hombre, en su estar en el mundo, debe dignificarse a través del compromiso que lo lleve, por medio de la práctica política, a estadios superiores de despliegue de su subjetividad y, por lo tanto, de su libertad.

Bibliografía Aron, Raymond, Dimensiones de la conciencia histórica. Tecnos, Madrid, 1962.

Cioran, Emile, Historia y Utopía. Tusquets, Barcelo na, España, 1988.

Fromm, Erich, ¿Tener o ser?, Fondo de Cultura Económica, México, 1988.

Fuentes, Carlos, Valiente mundo nuevo. Fondo de Cultura Económica, 1990.

H abermas, Jurgen, Problemas de legitimación en el capitalismo tardío. Amorrortu. Buenos Aires, 1991.

Kosik, Karel, Dialéctica de lo concreto. Enlace-G rijalbo. México, 1967. Kurnitzky, Hornst, Vertiginosa Inmobilidad. Blanco y negro. México, 1998.

León, Emma, El magma constitutivo de la historicidad. Anthropos, México, 1997.

Luminato, Susana, "La función de los valores en el pensamiento filosófico latinoaméricano", en Determinismos y alternativas en las Ciencias Sociales de América Latina. N ueva Sociedad. C aracas, Venezuela, 1995.

Zemelman, Hugo, Problemas antropológicos y utópicos del conocimiento. El Colegio de México. México, 1997.

- De la historia a la política. Siglo XXI, México, 1989. Venezuela, 1995. 